\title{
Cultural concerns in the use of coercion Marianne Kastrup
} Address: Center Transcultural Psychiatry, Psychiatric Clinic RIgshospitalet, Blegdamsvej, 2100 Copenhagen, Denmark
from WPA Thematic Conference. Coercive Treatment in Psychiatry: A Comprehensive Review

Dresden, Germany. 6-8 June 2007

Published: 19 December 2007

BMC Psychiatry 2007, 7(Suppl I):S60 doi:10.1 186/I47I-244X-7-SI-S60

This abstract is available from: http://www.biomedcentral.com/I47I-244X/7/SI/S60

(c) 2007 Kastrup; licensee BioMed Central Ltd.

A nationwide register based study has been carried out of all persons in contact with mental health services in Denmark in 2003. The study comprises 42,387 Danes and 8,247 non-Danes. The non-Danish group was divided into 4 subgroups: Adoptee (266); persons born abroad and at least one parent born abroad $(4,842)$; persons born in Denmark of parents both abroad (435); and persons born in Denmark of one parent born abroad and one in Denmark $(2,944)$. The vast majority of contacts are voluntary but both in men and women the ethnic minorities are more likely to be admitted non-voluntarily. Legal forensic measures are seen more commonly in men and more commonly in the ethnic minority groups. Contacts due to a Z-code (ICD-10) of forensic evaluation or observation are more than twice as high in men from an ethnic minority compared with men of a Danish background and men from an ethnic minority are also more likely to receive a psychiatric sentence. The present paper will focus on problems and issues of concern related to the use of coercion in patients from other ethnic groups. The focus will be on facets of international relevance with the aim to strengthen the quality of coercive treatment care for these groups. 